\title{
İki yeni kulak burun boğaz uzmanının ilk bir yıllık sürede yaptıkları ameliyatların ve komplikasyonlara yaklaşımlarının retrospektif değerlendirilmesi
}

\section{Retrospective evaluation of the operations and approaches to the complications of the two new ear nose throat specialists for the first year}

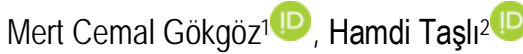 \\ 1 Siirt Devlet Hastanesi, Kulak Burun Boğaz Kliniği, Siirt, Türkiye, \\ 2 Şanlıurfa Birecik Devlet Hastanesi, Kulak Burun Boğaz Kliniği, Şanlıurfa, Türkiye
}

Öz.

Amaç: Güneydoğu Anadolu Bölgesi'nde birisi il merkezi, birisi ilçe merkezinde çalışan iki yeni Kulak Burun Boğaz (KBB) uzmanının, uzmanlıklarının ilk yılında yaptıkları ameliyatların sayısı, çeşitliliği ve komplikasyonları değerlendirildi. Ameliyatların ve komplikasyonların detaylı analizi yapılarak halen asistanlık eğitimi devam eden KBB hekimlerine nasıl bir gelecekle karşılaşacakları konusunda fikir vermesi amaçlandı.

Materyal ve Metot: Her iki hekimin 1 Şubat 2017 ile 1 Şubat 2018 tarihleri arasında ameliyat kayıtları incelendi. Bulgular: İ merkezinde çalışan hekimin 205, diğer hekimin 165 ameliyat yaptığı görüldü ve ameliyatlar çeşitlerine göre gruplandırıldı. KBB pratiğinde en sık yapılan ameliyatların oranları belirlendi. Adenoidektomi, Tonsillektomi ve Ventilasyon Tüp İnsersiyonu oranı il merkezinde çalışan hekimde $\% 35.5$, ilçe merkezinde çalışan hekimde \%25.6 olarak belirlendi. Septoplasti oranı sırasıyla \%21 ve 15.8, Septorinoplasti oranı \%10.4 ve $\% 12.8$ olarak belirlendi. Timpanoplasti oranı sırasıyla $\% 15$ ve $\% 9.75$ olarak belirlendi. Lenf nodu, kist ve lipom eksizyonları oranı sırasıyla \% 5 ve $\% 7.3$ olarak belirlendi.

Sonuç: Her KBB uzmanı mezun olurken temel ameliyatları etkin bir şekilde yapabilme yeteneğini kazanmış olmalıdır. Karşılaşılan komplikasyonlara karşı tedavi seçeneklerinin ve nasıl müdahale edilmesi gerektiğinin bilinmesi diğer önemli noktadır.

Anahtar Kelimeler: Otorinolaringolojik hastalıklar, Adenoidektomi, Timpanoplasti

Abstract

Background: In the Southeastern Anatolia Region, two new Ear Nose and Throat (ENT) specialists, one in the provincial center and one in the district center, were evaluated for the number, variety and complications of their operations in the first year of their specialty. A detailed analysis of the surgeries and complications was done and it was aimed to give an idea about the future of the ENT physicians who are still studying assistantship. Methods: The records of surgeries between February 1, 2017 and February 1, 2018 were reviewed.

Results: The physician working at the province center performed 205, the other physician performed 165 operations. The operations were grouped according to their types. The rates of the most frequent operations in ENT practice were determined. The ratio of adenoidectomy, tonsillectomy and ventilation tube insertion were determined as $35.5 \%$ in the physician working in the province center and $25.6 \%$ in the physician working in the district center. The rate of septoplasty was $21 \%$ and $15.8 \%$, and the rate of septorhinoplasty was $10.4 \%$ and $12.8 \%$ respectively. The rate of tympanoplasty was $15 \%$ and $9.75 \%$, and the ratio of lymph node, cyst and lipoma excision was determined as $5 \%$ and $7.3 \%$, respectively.

Conclusion: Every ENT specialist should be able to perform basic operations effectively while graduating. Treatment options and approaches to the complications should be known.

Keywords: Otorhinolaryngologic diseases, Adenoidectomy, Tympanoplasty

\section{Sorumlu Yazar I \\ Corresponding Author}

\section{Dr. Mert Cemal GÖKGÖZ}

Siirt Devlet Hastanesi,

Kulak Burun Boğaz Kliniği, 56100 Siirt /Türkiye

Tel: +90 (507) 7621385

E-mail: drmcgokgoz@gmail.com

Geliş tarihi / Received: 08/04/2019

Kabul tarihi / Accepted: 23/07/2019

DOI:10.35440/hutfd. 551076 


\section{Giriş}

Tıp fakültesinden yeni mezun olan doktorların pratisyenlik görevleri sırasında uygulama noktasında zorluklarla karşılaşı̆̆ı bilinmektedir. Aynı şekilde asistanlık eğitimi ve sonrasında uzmanlık görevleri sırasında da benzer zorluklarla karşılaşıımaktadır (1). Çalışmamızda, Güneydoğu Anadolu Bölgesi'nde birisi il merkezi, birisi ilçe merkezinde çalışan iki yeni Kulak Burun Boğaz (KBB) uzmanının, uzmanlıklarının ilk yılında yaptıkları ameliyatların sayısı, çeşitliliği ve karşılaştıkları komplikasyonları değerlendirerek halen asistanlık eğitimi devam eden KBB hekimlerine uzmanlık sırasında nasıl bir gelecekle karşılaşacakları konusunda fikir vermesi amaçlanmışıtı. Aynı zamanda karşılaşılan komplikasyonlara karşı nasıl bir yol izlenmesi gerektiğinden bahsedilmiştir.

\section{Materyal ve Metod}

Her iki hekimin 1 Şubat 2017 ile 1 Şubat 2018 tarihleri arasında yaptıkları ameliyat kayıtları ayrı ayrı incelendi. Hastaların demografik olarak yaş ve cinsiyet bilgileri kayıt altına alındı. Ameliyatların sayısı, çeşitliliği, hangi cerrahi yöntemin kullanıldığı ve karşılaşılan komplikasyonlar kayıt altına alındı. KBB pratiğinde en sık yapılan ameliyatların oranları belirlendi. Retrospektif olarak tasarlanan çalışmada elde edilen bulgular tanımlayıcı istatistiklerle özetlendi. Çalışma için Ankara Keçiören Eğitim ve Araştırma Hastanesi Etik Kurul'dan onay alındı (2018/1743). Ameliyat fotoğrafı kullanılan hastalardan yazııı bilgilendirilmiş onam alındı.

\section{Bulgular}

III merkezinde çalışan hekimin 205, ilçe merkezinde çalışan hekimin 165 ameliyat yaptığı görüldü ve ameliyatlar çeşitlerine göre gruplandırıldı. İl merkezinde çalışan KBB uzmanının yaptığı ameliyatlarda yaş ortalaması $24 \pm 10.6$ yıl ve aralığı 3-58 yıl, ilçe merkezinde çalışan uzmanın ise $23 \pm$ 9.5 yıl ve aralığı $5-48$ yıl olarak belirlendi. İ merkezinde çaışan KBB uzmanının yaptığı ameliyatların \%58'i erkek ve $\% 42$ 'si kadın olarak belirlenirken ilçe merkezinde çalışan uzmanın ise $\% 61$ 'i erkek ve $\% 39$ 'u kadın olarak tespit edildi. KBB pratiğinde en sık yapılan ameliyatlar olan adenoidektomi, tonsillektomi ve ventilasyon tüp insersiyonu oranı il merkezinde çalışan hekimde $\% 35.5$, ilçe merkezinde çalışan hekimde $\% 25.6$ olarak belirlendi. Her iki hekiminde tonsillektomi için soğuk bıçak ve bipolar koter yardımıyla tonsillektomi yaptıkları ve adenoidektomi için klasik küretaj yönteminin seçildiği belirlendi. Septoplasti oranı sırasıyla $\% 21$ ve 15.8 , septorinoplasti oranı $\% 10.4$ ve $\% 12.8$ olarak belirlendi. Septorinoplasti vakalarının tamamında her iki uzmanın da açık tekniği kullanıldığı saptandı. Timpanoplasti oranı sırasıyla $\% 15$ ve $\% 9.75$ olarak belirlendi. Timpanoplasti için her iki uzmanında vakaların \%90'ında endoskopik yolla transkanal kartilaj timpanoplastiyi tercih ettikleri görüldü. Lenf nodu, kist ve lipom eksizyonları oranı sırasıyla $\% 5$ ve $\% 7.3$ olarak belirlendi. İl merkezinde çalışan hekimde azalan oranlarda endoskopik sinüs cerrahisi, mastoidektomi, total tiroidektomi, süperfisyel parotidektomi, süspansiyon laringoskopi, Sistrunk, uyku cerrahisi, trakeotomi, nazal septum perforasyon tamiri ve lokal ameliyatlar gerçekleştirilmiş olup, ilçe merkezinde çalışan hekimde ise endoskopik sinüs cerrahisi, cilt tümör ve nevüs eksizyonları, dakriyosistorinostomi ve lokal ameliyatların gerçekleştirildiği görüldü (Tablo 1).

Komplikasyonlar değerlendirildiğinde il merkezinde çalışan uzmanın birer hastasında adenoidektomi sonrası kanama, süperfisyel parotidektomi ameliyatı sonrası geçici periferik fasiyal paralizi, septoplasti sonrası septal hematom saptandı. İlçe merkezinde çalışan uzmanın ise septoplasti sonrası septal hematom, septoplasti sonrası kaudalde minimal perforasyon saptandı. Her iki uzmanın birer timpanoplasti ameliyatı yapılan hastasında timpanik membran anteriorunda hilal şeklinde perforasyon saptandı.

Yeni Kulak Burun Boğaz uzmanı olan her iki hekimin yaptığı temel ameliyatların analizi yapıldığında il merkezinde çalışan uzmanın ameliyatlarının \%82.9' unu adenoidektomi, tonsillektomi, ventilasyon tüp insersiyonu, septoplasti, septorinoplasti, timpanoplasti, endoskopik sinüs cerrahisi oluştururken, ilçe merkezinde çalışan hekimde bu oran $\% 73$ olarak belirlendi.

\section{Tartışma}

KBB uzmanlarının, asistanlık sonrasında çalıştıkları ilk görev yerlerinde gerek poliklinik ve klinik hasta takiplerinde, gerekse yaptıkları ameliyatlarda çeşitli zorluklar yaşanmaktadır. Sürekli kendilerini kontrol eden ve destekleyen tecrübeli uzman, doçent ve profesörlerin olduğu bir klinikten ayrılıp yeni bir hastanede KBB açısından en yetkili kişi konumuna gelmenin getirdiği zorluklar kaliteli ve yeterli bir asistanlık eğitimi ile aşılabilir. Birinci basamak ve ikinci basamak sağlık merkezlerinde çalışan pratisyen, aile hekimi ve acil hastalıkları uzmanlarının KBB alanında yetersiz bilgive sahip oldukları ve fakültelerde KBB eğitiminin arttırıması fikri gelişmiş ülkelerde de tartışılmaktadır $(2,3)$. Yeni mezun olan uzmanların hem hastalarına faydalı olabilme ve kendini ispatlama içgüdüsü hem de hastanenin KBB alanındaki en yetkili kişisi olması sorumlulukları artırmaktadır. Biz çalışmamızda özellikle ameliyat çeşitliliği ve ameliyat sonrası gelişen komplikasyonlara yaklaşım tarzlarından bahsederek asistanlık süreci devam eden hekimlere yol göstermeyi amaçladık.

Temel KBB ameliyatları bütün dünyada adenoidektomi, tonsillektomi, ventilasyon tüp insersiyonu, septoplasti, septorinoplasti, miringoplasti/timpanoplasti, lenf nodu/kist eksizyonları olarak kabul görmektedir (4). 
Tablo 1. II ve İlçede Çalışan Uzmanların Ameliyat Oranları

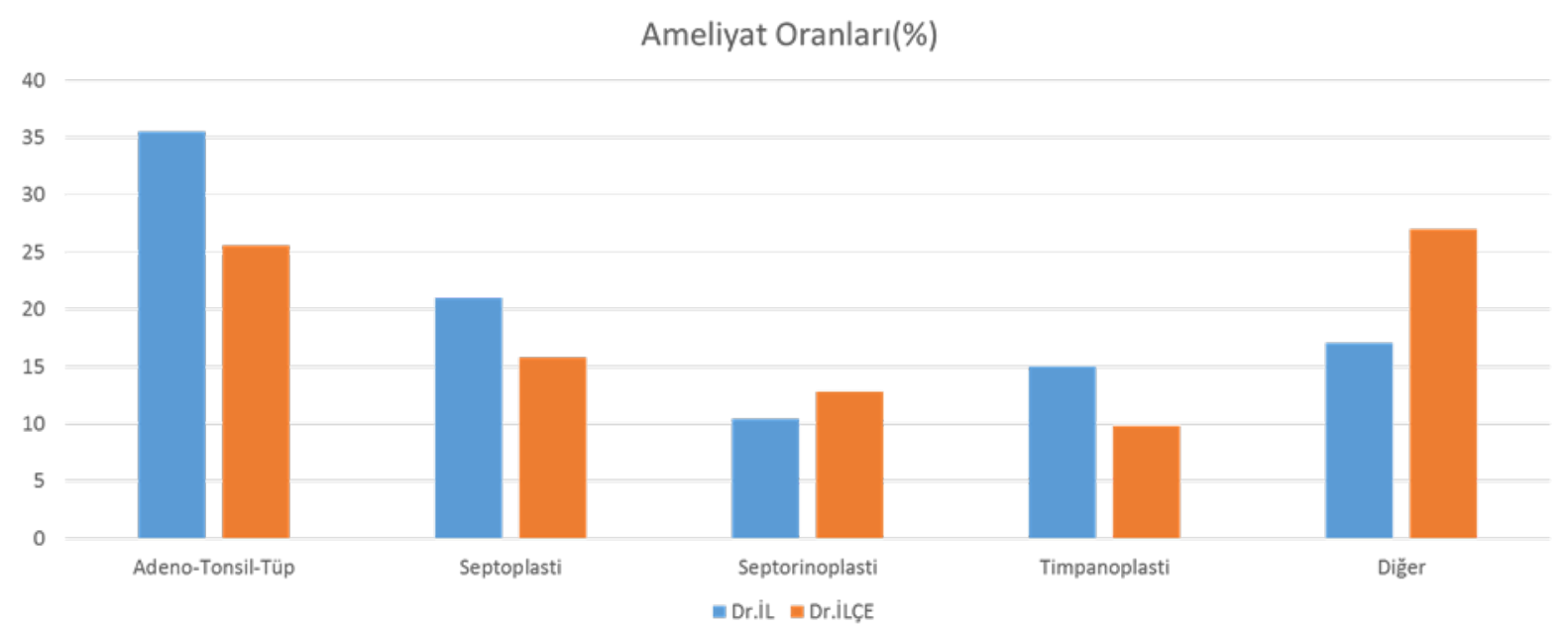

Yeni uzmanların yaptıkları ameliyat oranlarıyla ilgili çalışmalara bakıldığında bizim ülkemizden farklı olarak özellikle otolojik, fasiyal plastik ameliyatların ve daha fazla tecrübe gerektiren parotidektomi, tiroidektomi gibi baş boyun ameliyatlarının daha az uygulandığının görüyoruz (4).

Adenoidektomi, tonsillektomi ve ventilasyon tüp insersiyonu ameliyatı en sık yapılan ameliyat olmakla birlikte sıkIıkla çocuk popülasyona uygulanması ve komplikasyon gelişmesi halinde acil müdahale gerektirmesi nedeniyle önemlidir. Adenoidektomi ve tonsillektomi endikasyonlarl; kesin endikasyonlar olarak; obstruktif uyku apnesi ile beraber adenotonsiller hiperplazi varlığı, gelişme geriliği veya anormal dentofasiyal gelişim, malign hastalık şüphesi ve hemorajik tonsil sayılabilir. Relatif endikasyon olarak üst hava yolu obstrüksiyonu yaratan adenotonsiller hipertrofi, konuşma bozukluğu, disfaji ve halitozis varlığı sayılabilir. Tekrarlayan otitis media, kronik sinüzit ve adenoidit, adenoidektomi için relatif endikasyonları oluşturur $(5,6)$. Tonsillektomi sonrası kanama sıklığı \%1-10 arasında değişmekle birlikte bizim çalışmamızda tonsillektomi sonrası kanama izlenmemiştir. Tonsillektomi sonrası kanamaların \% 15-20 si kanama kontrolü için ameliyat gerektirmektedir $(7,8)$. Bizim çalışmamızda komplikasyon olarak daha nadir olan adenoidektomi sonrası kanama izlenmiştir. Adenoidektomi sonrası kanama sıkığı çeşitli çalışmalarda \%00.49 arasında değişmektedir (9-11). Hastamız tekrar genel anestezi altında ameliyata alınmış, posterior tampon sonrası sızıntı haline gelen kanama nazal endoskopiden görülerek ve ağız içinden bipolar koter adenoid ucu yardımıyla koterize edilerek kontrol altına alınmıştır. Takiplerinde kanama izlenmeyen hasta post operatif 2. günde taburcu edilmiştir. Adenotonsillektomi sonrası en sık izlenen komplikasyonlar kanama, ses bozukluğu, yutma bozuklukları, atlantoaksiyal subluksasyon ve anesteziden uyanma sırasında solunum problemleri olarak sayılabilir. Obstruktif uyku apnesi nedeniyle adenoidektomi/tonsillektomi ameliyatı yapılan hastalarda solunumsal komplikasyonların 5 kat daha fazla yaşandığını gösteren çalışmalar mevcuttur
(12). Adenoidektomi kanamalarında kontrol sağlanması amacıyla koterizasyon ve posterior tampon uygulamaları yapılabilir. Adenoidektomi sonrası kanamayı kontrol altına almak için posterior tamponun 1 gün kalmasını savunan yaklaşımlarda mevcuttur (13).

Septoplasti, burun tıkanıklığı yakınması ile başvuran hastalarda anterior rinoskopik ve endoskopik muayene sonrasında nazal septumda saptanan eğrilikler sonucu karar verilen ve sık uygulanan bir ameliyattır. Hastaların burun dış görünümünden rahatsı olması halinde ve ya septum ile beraber nazal çatıda mevcut olan eğriliklerde septorinoplasti ameliyatı yapılmaktadır. Yazarlar septoplastide Kilian insizyonunu ya da hemitransfiksiyon insizyonunu tercih etmektedirler. Septorinoplastide ise açık tekniği tercih etmektedirler. Bir hastada gelişen septal hematom drene edilip tampon yerleştirilerek tedavi edilmiştir. 1 hastada gelişen kaudal yerleşimli minimal septal perforasyon ise lokal anestezi altında tamir edilerek perforasyon kapatımıştır. Septoplasti sonrası en sık izlenen komplikasyon kanamadır. Ameliyat sonrası meydana gelen kanamayı durdurmak için intraoperatif alınacak önlemler tampon ya da nazal splint uygulanması ve transseptal sütür sayılabilir. Nazal sineşi oluşumu, septal perforasyon, kafa tabanı hasarına bağlı beyin omurilik sıvısı fistülü ve koku alma bozukluğu diğer komplikasyonlardır. Ameliyat bitiminde intravenöz traneksamik asit uygulanmasını öneren çalışmalar mevcuttur (14).

Timpanoplasti ameliyatı için her iki uzmanında endoskopik metodu \%90 oranında kullandıkları görülmüştür. Endoskopik timpanoplastinin daha kısa ameliyat süresi, mikroskobik yöntemde görülmesi zor alanların endoskoplar ile daha görünür hale gelmesi, artan hasta konforu, daha kısa yatış süresi ve azalan pansuman intiyacı ile mikroskobik klasik yöntemle benzer cerrahi sonuçlara erişilmesi nedeniyle yazarlar tarafından tercih edilmektedir (15). Her iki uzmanında klasik mikroskobik cerrahi üzerine eğitim almasına rağmen endoskopik kulak cerrahisi hızlı öğrenme eğrisiyle 
güvenli bir şekilde uygulanmaktadır (16-20). Ameliyat sonrası timpanik membran anteriorunda kalan hilal şeklinde perforasyon kalan iki hastada da odyolojik açıdan kısmen ilerleme kaydedilmiştir ve hastalara kalan perforasyon için tekrar ameliyat yapılabileceği anlatılmıştır. Tekrar ameliyat olmayı kabul eden hastanın anterior kadranda kalan perforasyonu fasya ile kapatılmış ve kontrollerde greft zar intakt ve sağlıklı olarak izlenmiştir. Özellikle endoskopik timpanoplastiye bağlı komplikasyonlar değerlendirildiğinde endoskopun oluşturabileceği mekanik hasar, ksenon ışık kaynağının oluşturabileceği termal hasar, greft başarısızIığı, korda timpani hasarına bağı tat alma bozukluğu, fasiyal sinir hasarına bağlı kalıcı ya da geçici fasiyal paralizi ile greft alınan sahada oluşan hematom ve ağrı sayılabilir (21).

Az sıkıkta yapılan iki total tiroidektomi ve iki süperfisyel parotidektomi ameliyatı sırasında sinir monitorizasyonu, sinir bulunduktan sonra teyit amacıyla kullanılmıştır (22). Superfisyel parotidektomi sonrası grade 4 periferik fasiyal paralizi gelişen hasta oral steroid tedavisi sonrasında tamamen düzelmiş olup fasiyal paralizinin ameliyat sırasında traksiyonlara bağlı olarak geliştiği düşünülmektedir. Periferik fasiyal paralizi gelişen hastada sinirin bütün dalları ile intakt şekilde olduğu imaj aşağıda görülmektedir (Şekil 1). Parotidektomi sonrası geçici ve ya kalıcı periferik fasiyal paralizi, greater auriküler sinir hasarına bağı his kaybı, kanama, hematom ve yara yeri enfeksiyonu, fistül oluşumu ve geç dönemde Frey sendromu komplikasyonlar arasında sayılabilir (23).

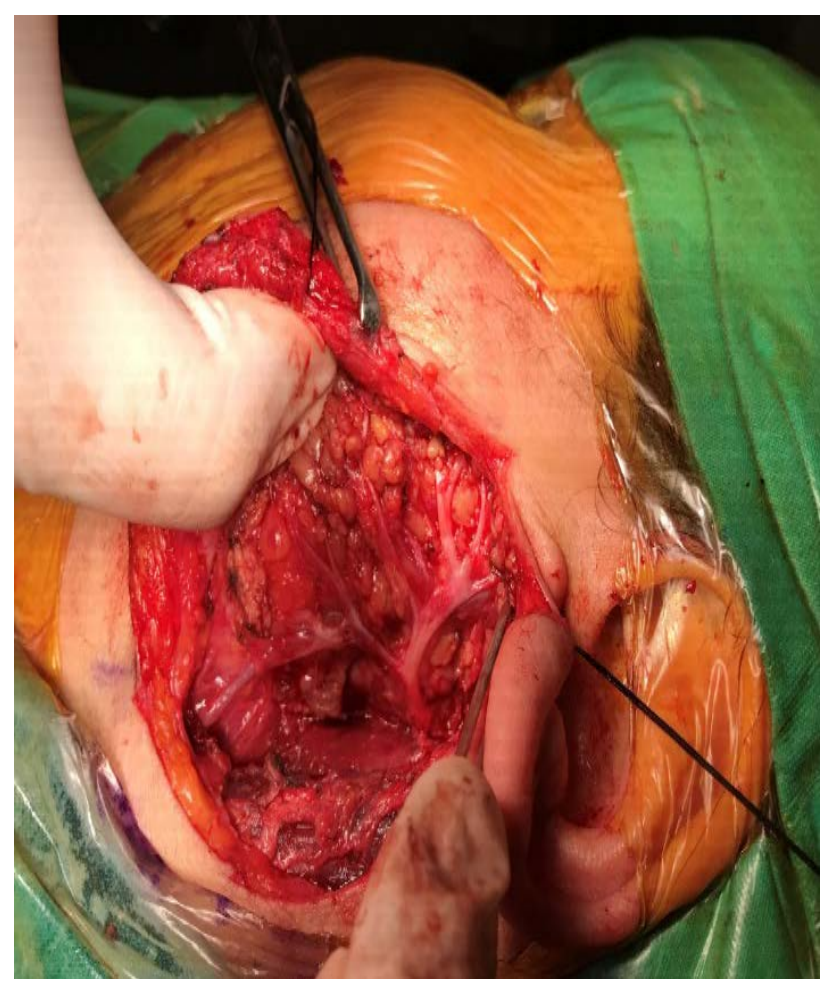

Şekil 1. Sol Süperfisyel Parotidektomi Sırasında Eksplore Edilen Fasiyal Sinir Görünümü.
Asistanlık eğitimi sonrasında öğrenme süreci bir hekim için hayat boyu sürmektedir. Günümüzde değişen eğitim stratejileri ile ana kitaplar, dersler, makaleler, kongreler ve kadavra kursları dışında internet yoluyla öğrenme süreci de giderek önemli hale gelmektedir $(24,25)$. Bu konuda yapılan bir derlemede internet tabanlı öğrenme stratejilerinin klasik eğitime alternatif olabileceği ve bu yenilikçi platformlarını kullanılarak uzun vadeli bilgi birikimine ulaşılabileceği ifade edilmektedir (26). Uzun zamandır yapılmayan ya da yetersiz hissedilen ameliyatların öncesinde çeşitli ameliyat videolarının izlenmesi ve diğer görsellerin incelenmesi fayda sağlayabilir. Birden fazla KBB uzmanının çalıştığı hastanelerde diğer uzmanın tecrübelerinden ve kendisini daha rahat hissettiği cerrahi alanlardan faydalanılabilir. Her KBB uzmanı mezun olurken temel ameliyatları etkin bir şekilde yapabilme yeteneğini kazanmış olmalıdır. Karşılaşılan komplikasyonlara karşı tedavi seçeneklerinin ve nasıl müdahale edilmesi gerektiğinin bilinmesi diğer önemli noktadır. Her uzman için eğitim ve öğrenme bitmeyen bir süreçtir ve klasik öğrenme yöntemlerinin yanı sıra internet tabanlı programlar ile de uzun dönem öğrenme sağlanabilir.

\section{Kaynaklar}

1. Gander P, Briar C, Garden A, Purnell H, Woodward A. A genderbased analysis of work patterns, fatigue, and workllife balance among physicians in postgraduate training. Acad Med. 2010;85(9):1526-1536.

2. Hu A, Sardesai MG, Meyer TK. A need for otolaryngology education among primary care providers. Med Educ Online. 2012;17: 17350.

3. O'Brien DC, Squires LD, Robinson AD, Ramadan H, Diaz R. A Multicenter, Cross-Sectional Assessment of Otolaryngology Knowledge Among Primary Care Trainees. Ann Otol Rhinol Laryngol. 2018;127(9):631-636

4. Eskander A, Campisi P, Witterick IJ, Pothier DD. Consultation diagnoses and procedures billed among recent graduates practicing general otolaryngology - head \& neck surgery in Ontario, Canada. J Otolaryngol Head Neck Surg. 2018;47(1):47.

5. Patel HH, Straight CE, Lehman EB, Tanner M, Carr MM. Indications for tonsillectomy: a 10 year retrospective review. Int J Pediatr Otorhinolaryngol. 2014;78(12):2151-2155.

6. Darrow $\mathrm{DH}$, Siemens $\mathrm{C}$. Indications for tonsillectomy and adenoidectomy. Laryngoscope. 2002;112:6-10.

7. Whelan RL, Shaffer A, Anderson ME, Hsu J, Jabbour N. Reducing rates of operative intervention for pediatric post-tonsillectomy hemorrhage. Laryngoscope. 2018;128(8):1958-1962.

8. Kapusuz Z, Sakallıoğlu Ö, Göçmen Y, Saydam L. Cerrahi Teknik Seçiminin Tonsillektomi Sonrası Kanama Olasılığı Üzerine Etkisi. Firat Tıp Dergisi 2012; 17(1): 36-39

9. Tomkinson A, Harrison W, Owens D, Fishpool S, Temple M. Postoperative hemorrhage following adenoidectomy. Laryngoscope. 2012;122(6):1246-1253.

10. Demirbilek N, Evren C, Altun U. Postadenoidectomy hemorrhage: how we do it? Int J Clin Exp Med. 2015;8(2):2799-2803

11. Salihoğlu M, Çalışkan H, Çakmak A. Adenoidektomi sonrası endoskopi ve ayna ile nazofarenks değerlendirmesinin tedavi sonucuna etkisi. Kulak Burun Boğaz Uygulamaları 2013;1(2):58-63

12. De Luca Canto G, Pachêco-Pereira C, Aydinoz S, Bhattacharjee R, Tan HL, Kheirandish-Gozal L et al. Adenotonsillectomy Complications: A Meta-analysis. Pediatrics. 2015;136(4):702-18

13. Tzifa KT, Skinner DW. A survey on the management of reactionary haemorrhage following adenoidectomy in the UK and our practice. 
Clin Otolaryngol Allied Sci 2004; 29: 153-156

14. Zaman SU, Zakir I, Faraz Q, Akhtar S, Nawaz A, Adeel M. Effect of single-dose intravenous tranexamic acid on postoperative nasal bleed in septoplasty. Eur Ann Otorhinolaryngol Head Neck Dis. 2019 Jun 13. pii: S1879-7296(19)30115-2. doi: 10.1016/j.anorl.2018.10.019. [Epub ahead of print]

15. Sürmelioğlu Ö, Özdemir S, Tarkan Ö, Tuncer Ü. Kronik otitis media tedavisinde transkanal endoskopik timpanoplasti. Kulak Burun Bogaz Ihtis Derg 2014;24(6):330-333

16. Özgür A, Dursun E, Erdivanli ÖÇ, Coşkun ZÖ, Terzi S, Emiroğlu G et al. Endoscopic cartilage tympanoplasty in chronic otitis media. J Laryngol Otol. 2015;129(11):1073-1077.

17. Choi N, Noh Y, Park W, Lee JJ, Yook S, Choi JE et al. Comparison of Endoscopic Tympanoplasty to Microscopic Tympanoplasty. Clin Exp Otorhinolaryngol. 2017;10(1):44-49.

18. Kuo CH, Wu HM. Comparison of endoscopic and microscopic tympanoplasty. Eur Arch Otorhinolaryngol. 2017;274(7):2727-2732.

19. Tseng CC, Lai MT, Wu CC, Yuan SP, Ding YF. Learning curve for endoscopic tympanoplasty: Initial experience of 221 procedures. J Chin Med Assoc. 2017;80(8):508-514.

20. Dogan S, Bayraktar $C$. Endoscopic tympanoplasty: learning curve for a surgeon already trained in microscopic tympanoplasty. Eur Arch Otorhinolaryngol 2017;274(4):1853-1858

21. Gokgoz MC, Tasli H, Helvacioglu B. Results of endoscopic transcanal tympanoplasty performed by a young surgeon in a secondary hospital. Braz J Otorhinolaryngol. 2019 Feb 28, pii: S18088694(18)30540-8. doi: 10.1016/j.bjorl.2018.12.012. [Epub ahead of print]

22. Öztürk K, Göde S, Gürsan G, Kirazı। T. Parotidektomi sırasında monitörizasyon ile ameliyat sonrası fasiyal sinir fonksiyonu öngörülebilir mi? Kulak Burun Bogaz Ihtis Derg 2015;25(1):28-31

23. Akçam MT, Karakoç Ö, Karahatay S, Gerek M. Yüzeysel parotidektomi sonrası nöral komplikasyonlar. KBB-Forum. 2005; 4(2): 56-60

24. Tsai Do BS. Reflections on the Changing Platform of Education for the Budding Otolaryngologist. Otolaryngol Head Neck Surg. 2015;153(5):706-707.

25. Hughes JP, Quraishi MS. YouTube resources for the otolaryngology trainee. J Laryngol Otol. 2012;126(1):61-62

26. Tarpada SP, Hsueh WD, Gibber MJ. Resident and student education in otolaryngology: A 10-year update on e-learning. Laryngoscope. 2017;127(7):219-224 